\title{
Application Analysis of Mobile Learning Tools in Modern Distance Education
}

\author{
Shi Yang \\ Vocational Education Center, Naval University of Engineering, PLA, 430033, China
}

Keywords: distance education; mobile learning; application scenario

\begin{abstract}
As a traditional education method that is different from face-to-face teaching, distance education has become an increasingly important educational method in today's society because of its convenience and flexibility. With the development of communication technology and intelligent device terminals, we have entered the information age, with the further improvement of the speed and effect of information dissemination, the way of distance education has increased more selectivity. Mobile learning tools are an important carrier for distance education activities, and have a good effect on distance education. This paper analyzes the characteristics of distance education and mobile learning tools, demonstrates the feasibility of mobile learning in modern education and the remote autonomous learning model based on mobile learning, and then expounds the mobile learning tools in modern remote Application scenarios in education.
\end{abstract}

\section{Introduction}

Distance education is a product of information technology applied in the field of education. As a product of information technology, mobile learning tools have many application scenarios in the field of distance education, which has a very important impact on the effectiveness of distance education. This paper clarifies the concept of distance education and mobile learning tools, and expounds its characteristics, and demonstrates the feasibility and application scenarios of mobile learning tools in modern distance education.

\section{The concept and characteristics of distance education}

Modern distance education refers to the collection, design, development and utilization of various educational resources and the construction of an educational environment by a specific educational organization that comprehensively applies technology in a certain social period, and based on the technology, educational resources and educational environment of a certain social period. Students provide educational services, as well as organizing some group meeting exchanges (in traditional face-to-face or in modern electronic form) for the purpose of teaching and socialization, to help and promote all practical activities for the purpose of distance learning for students. In all activities, the teacher maintains a quasi-permanent separation from the student in the form of educational resources or as a learning facilitator; and students and educational organizations (teachers) or students and students will be established through A two-way or multi-directional communication mechanism maintains an instant session. Modern distance education in China is sometimes called online education. Most modern distance education institutions engaged in higher education are network education colleges or modern distance education colleges of ordinary universities. Online education is a new concept generated by the application of modern information technology in education. It is the use of network remote technology and environment education. In some documents already issued by the Ministry of Education, modern distance education is also called online education. Modern distance education can effectively play the characteristics of distance education. It is a kind of teaching activity relative to face-to-face education, separation of teachers and students, and non-face-to-face organization. It is a cross-school and cross-regional education system and teaching mode. Its characteristics is: students are separated from teachers; teaching is carried out using specific transmission systems and communication media; information is transmitted in a variety of ways; the places and forms of learning are flexible. Compared with 
face-to-face education, the advantage of distance education is that it can break through the limitations of time and space; provide more learning opportunities; expand the scale of teaching; improve the quality of teaching; and reduce the cost of teaching. Based on the characteristics and advantages of distance education, many people of insight have recognized the importance and broad prospects of developing distance education. Every development of distance education is inseparable from the communication technology of educational resources. With the increasing maturity of the three educational resources of broadcasting, television and internet, mobile communication technology continues to develop, and mobile terminals are also beginning to bear as new carriers. In order to enable distance education learners to learn more easily and flexibly, truly experience the advantages of "five any" (anyone, any time, any place, starting from any chapter, learning any course) in distance education, in distance education. From a perspective, building a better mobile learning system suitable for distance education learners is an urgent task for current distance education institutions.

\section{The concept and characteristics of mobile learning tools}

Mobile learning refers to relying on the more mature wireless mobile networks, the Internet, and multimedia technologies. Students and teachers can use the more commonly used wireless devices (such as mobile phones, PDAs, laptops, etc.) to achieve more convenient and flexible interaction. Teaching activities, as well as information exchange in education and technology. It mainly consists of three parts: firstly, mobile learning is based on digital learning by some portable mobile devices; secondly, mobile learning relies on mobile communication technology and through it to realize the transmission of educational content and educational service information; thirdly, teaching and learning in mobile learning the interactivity of activities must be supported and implemented by mobile technologies. It is a learning that can occur anywhere, anywhere with the help of a mobile device. The mobile computing device used for mobile learning must be able to effectively present learning content and provide two-way communication between the teacher and the learner. First of all, mobile learning is developed on the basis of digital learning. It is an extension of digital learning, which is different from general learning. Secondly, in addition to all the features of digital learning, mobile learning has its unique characteristics. That is, the learner is no longer restricted to the computer desk, and can freely and independently learn at different purposes and in different ways. The learning environment is mobile, and the teachers, researchers, technicians, and students are all mobile. Finally, from In terms of its implementation, the technical basis of mobile learning implementation is mobile computing technology and Internet technology, namely mobile interconnection technology; the implemented tools are miniaturized mobile computing devices, and the devices implemented for mobile learning are characterized by features. Such an analysis: portability, that is, the device is small in shape, light in weight, and easy to carry around; wireless, that is, the device does not need to be connected; mobility, which means that the user can also use it well during the movement.

Table 1

\begin{tabular}{|c|c|c|}
\hline \multicolumn{2}{|c|}{ Comparison between digital learning and mobile learning } \\
\hline category & digital learning & mobile learning \\
\hline Learning space & Limited by Internet conditions & $\begin{array}{c}\text { Large degree of freedom, where there } \\
\text { are mobile signals }\end{array}$ \\
\hline study-time & $\begin{array}{c}\text { freedom, but still limited by } \\
\text { Internet conditions }\end{array}$ & $\begin{array}{c}\text { Freedom of freedom, mobile } \\
\text { terminals release more learning time }\end{array}$ \\
\hline transfer method & Internet based mode & Mobile communication mode \\
\hline Learning resource format & Rich format & $\begin{array}{c}\text { Affected by screen size and traffic } \\
\text { charges of mobile terminals }\end{array}$ \\
\hline Learning personalization & More features & $\begin{array}{c}\text { Limited by technology, poor } \\
\text { personalization }\end{array}$ \\
\hline Interactive mode & Rich and diverse, easy to reply & $\begin{array}{c}\text { More abundant, more convenient to } \\
\text { reply }\end{array}$ \\
\hline
\end{tabular}




\section{Feasibility analysis of the application of mobile learning tools in modern distance education}

\subsection{Mobile learning hardware is nearing maturity}

Compared with other distance education methods, mobile learning does not need to invest in building new network systems. China's three major telecommunications operators have now developed into the world's largest wireless communication network, covering all parts of the country. It ensures the smooth flow of wireless communication at any time and any place. We can use this existing mature and advanced network system to borrow flowers and build our own mobile learning platform. In addition, mobile learning as a new market has also attracted attention and development by mobile operators and mobile device providers around the world. They are working hard to develop mobile learning devices and software that are small in size, light in weight, and easy to carry, reducing costs. In particular, the "mobile phone" of mobile learning tools is inexpensive, which makes mobile learning have a good implementation basis. Compared with a few years ago, the current mobile hardware platform is enough for learning. Whether it is CPU processing speed, memory size, multimedia effects, and screen resolution, the mobile communication system can be combined with modern distance education to form a mobile learning system. There will be a large number of potential learners.

\subsection{The software conditions for mobile learning are getting better and better}

At present, there are not many learning software based on mobile terminal platforms, mainly focusing on mobile phone-based e-books, MP3s, video clips, etc., and the learning content is relatively simple, focusing on a few subjects such as English. Fortunately, there are already some forward-looking research institutions in China that have begun to work on mobile learning platform software and course content resources, and the learning software has a multimedia trend. At present, many companies in China focus on developing learning software resources running on mobile phones, and some companies have developed mobile phone-based learning platforms. In addition, there are a lot of mobile learning resources developed by mobile phone learning enthusiasts. Learning resources based on Java, Symbian, Windows Mobile, and Palm platforms are rapidly enriching, forming a group of developers, advocates, and users of their respective platforms. It is believed that there will be a large number of mobile learning platforms and mobile learning resources in the near future.

\section{Distance learning model based on mobile learning}

Because modern distance education is guided by modern educational theories, computerized media and network communication technologies are used to organize teaching, implement learning, and communicate, thus completing the teaching organization of all aspects of the teaching process. In this kind of teaching organization, the separation of teachers and students in time and space requires that learners are highly responsible for their independent learning, that is, they can conduct autonomous learning. Mobile learning is an extension and extension of modern distance education. It has almost all the advantages of fixed distance learning, such as openness, system, multimedia, interactivity, virtuality, etc., and it is relative to fixed distance learning. It is also characterized by digitization, flexibility, portability and individuality. Compared with digital learning, in mobile learning, learners are no longer restricted to the computer desk, and can freely and independently learn different purposes and in different ways. The four basic elements of the teaching process: teachers, students, teaching content and teaching media are all "mobile". Therefore, applying mobile learning to modern distance education will make full use of its characteristics to give full play to the potential of learners to learn independently. In this learning process, learners reflect the five characteristics of self-identification, self-direction, self-reinforcement, self-adjustment, and self-control. In order to better reflect the above characteristics, this paper constructs a learning support system based on mobile terminal and a composite autonomous learning mode based on interactive, collaborative, individualized and self-monitoring learning processes. 


\section{The application of mobile learning tools in modern distance education}

\subsection{Mobile learning mode based on short message}

SMS is short for Short Message Service, which is a function of sending and receiving limited length text information through a mobile phone. The SMS takes up a short time and costs, which makes it easy for two GSM users to communicate peer-to-peer. At present, mobile phone terminals generally have this function, and no need to add any hardware and software modules. As a means of communication and communication, short message service has been widely used and won the favor of users. Mobile learning based on short messages is the simplest and fastest way to learn in mobile learning. Through short messages, limited characters can be transferred between students, between students and teachers, and between students and teaching servers, and between teachers and servers. By using this feature, users can communicate with the Internet through the wireless mobile network and complete certain teaching activities. Such teaching activities are no longer limited by time, place and place, and truly "everywhere, everytime" learning. Specific functions include: the school's notification of the teacher's teaching activities; the teacher's notification of the student's teaching activities; the student's questions to the teacher; the teacher's questions and answers to the student's questions; the student's inquiry of the test scores, etc. The short message-based education method is suitable for teaching activities with less communication data and simple text description. The following is a system structure diagram based on the short message scheme.

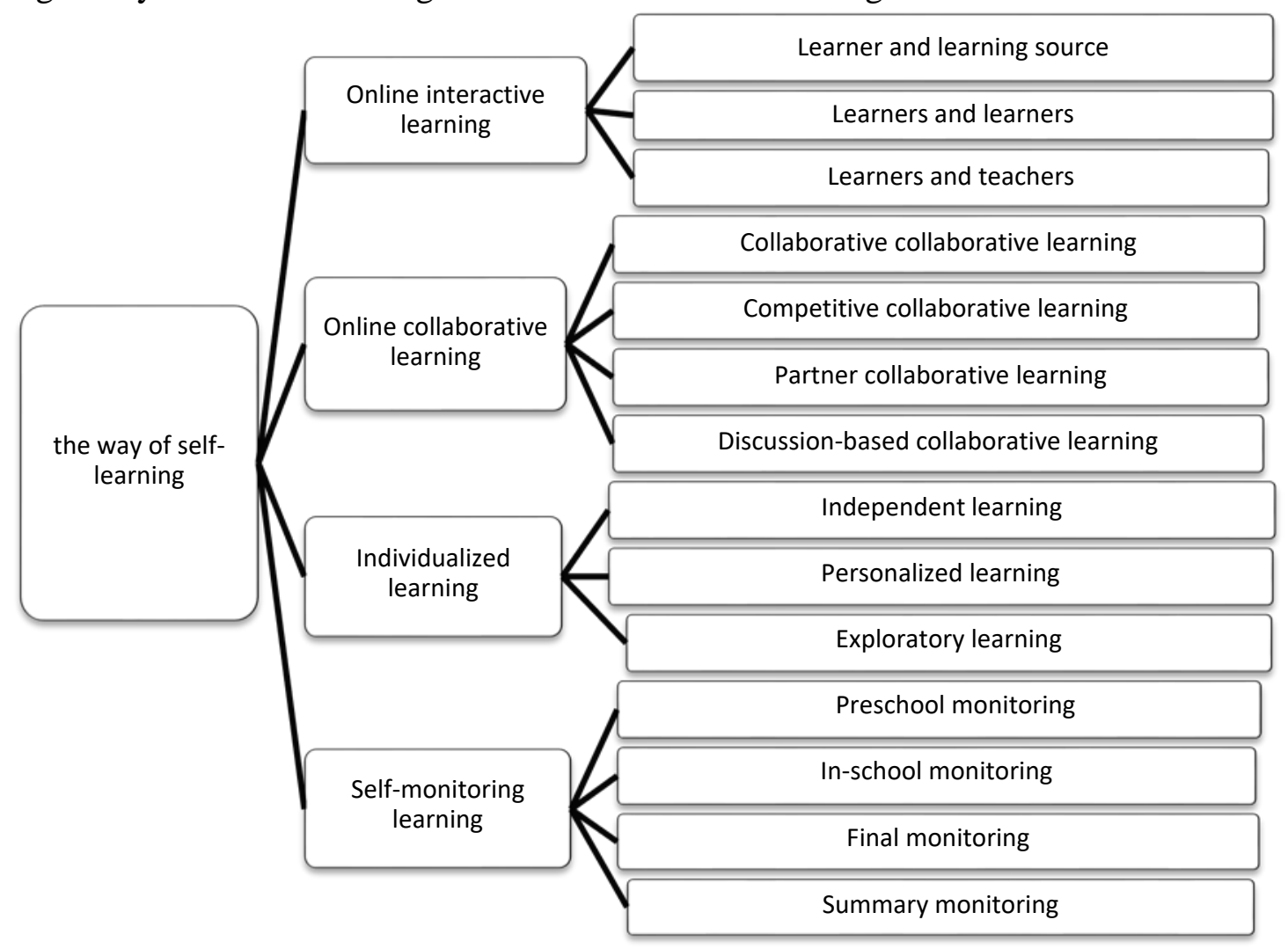

Fig.1 Mobile learning mode

\subsection{Connection-based mobile learning mode}

For short message communication, the communication of its data is intermittent and cannot be connected in real time, so it is impossible to use this kind of communication to realize the browsing of the website by the mobile phone, and it is difficult to realize the transmission and display of the multimedia resources. However, with the launch of the 4G communication protocol, browser-oriented mobile devices will soon be promoted. At this time, mobile learning will undergo unprecedented changes in convenience and quality of service: teaching activities will be free from time, space and Land restrictions, and will receive high quality assurance. However, the transition of the education platform from microcomputer to mobile device will also bring a series of problems. 
One is the problem of communication charges. Connection-oriented protocols will allow for long-term connections, and on-time charging will be very expensive, and many vendors currently recommend charging by traffic. The second is the format conversion problem. The mobile device screen has a very large gap with the computer screen, and its display format should be changed according to the size of the mobile device screen. The information received by mobile devices (mobile phones, PDAs, etc.) is based on WML (Wireless Markup Language), and the page files on general web servers are stored in HTML (Hypertext Markup Language) format. Therefore, when browsing Internet information online through a mobile device, the HTML file is converted into a W ML file. The current approach is to define a mobile-oriented markup language (WML) and to develop a set of middleware between HTML and WML. When browsing a web page with a mobile device, the middleware converts the HTML file into a WML file and transmits it to the mobile device for display. The third is to develop educational software based on mobile terminals. With the continuous innovation of technology, mobile devices are now more and more powerful enough to run multimedia applications such as Flash, MP3, MP4, etc., so that multimedia interactive learning effects similar to those of microcomputer learning software can be achieved. However, since many microcomputer software is based on a microcomputer screen, it is necessary to make appropriate modifications to the display program when migrating to a mobile device.

\section{Conclusion}

At present, mobile learning is transforming from theoretical research to applied research. Many distance education experts have done a lot of research on mobile learning, which lays a solid theoretical foundation for the application practice of mobile learning. This paper closely follows the current background of education informatization, and makes a simple analysis of the application scenarios of mobile learning from the perspective of distance education in order to provide some reference for the development of distance education. As the trend of intelligentization of mobile terminals is getting faster and faster, the popularity of smartphones is gradually increasing. The next step will be to study the application of mobile learning system clients in the field of distance education, so that distance education learners can enjoy mobile learning more conveniently and quickly.

\section{References}

[1] Filho M F, Klein L Z, Neto M F. M-learning tools on distance education: Overview and case study[C]// Education Engineering. 2010.

[2] Lu W, Jin Y. The Analysis on Application Effect of a Provincial Modern Distance Education Management Information System[C]// International Conference on Information Technology in Medicine \& Education. 2016.

[3] Bin G U. The MTI 3D Model for the Estimation of E-learning Tools in Higher Education Field [J]. Modern Distance Education, 2008(3).

[4] Omona W, Ikojaodongo R. Application of Information and Communication Technology (ICT) in Health Information Access and Dissemination in Uganda.[J]. Journal of Librarianship \& Information Science, 2006, 38(1):45-55.

[5] Roreger H, Schmidt T C. Socialize online learning: Why we should integrate learning content management with Online Social Networks[C]// IEEE International Conference on Pervasive Computing \& Communications Workshops. 2012.

[6] Shih S. A Knowledge-based Approach to Retrieving Teaching Materials for Context-aware Learning [J]. Journal of Educational Technology \& Society, 2009, 12(1):82-106. 